\title{
THE TIMID LOVER
}

Winter blows a blackest night

Upon the streets and unlit homes,

But she and I inside the light

Enjoy such warmth (the cold unknown).

The people chat and laugh and eat

The glasses clink and wine is sipped

My heart assumes a quicker beat

And leaves me of my senses stripped.

The chimney puffs a wisp of smoke It rises up to touch the sky; Inside, my eloquence is choked By her piercing, burning eye.

And in my heart there is a heat, Of which the wine is not the source, This warmth - with which I am repleteIs born in her, my Muse, of course.

And when it's time to rise and go, She rises too and leaves with me, Back among the cold and snow, I'm still as warm as I could be. 